\title{
El pensar como acción, la quietud como acción. Mito del hombre sentado
}

\author{
Thinking as action, \\ stillness as action. \\ Myth of the sitting man
}

\author{
Nury Vargas Hernández ${ }^{1}$ \\ Investigadora grupo BIOMA
}

\section{RESUMEN:}

En este escrito propongo mirar desde la filosofía del performace, la imagen del ritual y el mito El hombre sentado, que el profesor Fernando Urbina ha investigado en la región amazónica de Colombia. Los pictogramas y petroglifos que aparecen repetitivos específicamente en la región del Araracuara dan cuenta de una imagen, pero específicamente del mito que la precede. Mito que me lleva a pensar en la acción que hay en la quietud y en el estar sedente, en la acción que hay en el pensar y en el hablar, elementos que pretendo observar desde lo performático como forma de arte y como forma de entender

$1 \quad$ Maestra en Artes Plásticas. Universidad Nacional de Colombia

Correo:nvargash@unicolmayor.edu.co

Cargo: Profesora artes plásticas Programa de Ciencias Básicas. Investigadora grupo BIOMA

https://orcid.org/0000-0002-8210-6719

https://scienti.minciencias.gov.co/cvlac/visualizador/generarCurriculoCv.do?cod $r h=0000116006$ y asumir acciones que el ser humano produce y vive desde diferentes cotidianidades.

PALABRAS CLAVE: performance, mito, ritual, hombre sentado.

\section{SUMMARY}

In this paper I propose to look from the philosophy of performance, the image of ritual and the myth The Sitting Man, which Professor Fernando Urbina (1994), from the Universidad Nacional de Colombia has researched on the edge of the Caquetá River, in the Amazon region, and the way he assures it in his writings, from a direct approach to the indigenous communities of this extensive Colombian area. The pictograms and petroglyphs that recurrently appear, specifically in the region of the Araracuara give an account of an image, but specifically of the myth that precedes it. Myth that leads me to 
think about the existing action in stillness and in being sedentary, in the existing action in thinking and speaking, elements that I try to observe from the performative as a form of art and as a form of understanding and assuming actions that the human being produces and lives from different every day activities.

By assuming the myth and ritual of The Sitting Man as an object of study from the performative I structure the proposal and the development of the analysis having, among others, vertebral references such as Diana Taylor and Richard Schechner.

Thus, the reader will find a proposal to explore myth and ritual from the practice and concept of performance, which, as Taylor (2011) quotes, referring to Victor Turner, are exercises in which changes arise from their purpose, which may be as it was raised in its early days, artistic, but also political and as this writing assumes, sometimes ritual. In general it is a practice that transcends its own limits.

Similarly ,Schechner (2011)is key, as a reference that will be found in the performance analysis as a restored conduct, considering it a behavior or conduct that is repeated twice, that is as an event that does not just occur once.

KEY WORDS: performance, ritual, myth, sitting man.

"Entonces vio su sombra. Estaba allí, sentada. Se inventó la palabra y el eco respondió (el eco que es la sombra del sonido)"

Fragmento del mito de El Hombre Sentado (Urbina, 1994 p.106)

Siguiendo el fragmento del mito; una acción lleva a la otra, cada una debe existir para que la anterior y la siguiente cobren sentido. Al proponer el pensar como acción, la quietud como acción desde el mito de El Hombre sentado se desencadenan tres momentos, cada uno enlaza con el siguiente siendo parte de un mismo tejido.

\section{PRIMER MOMENTO}

\section{PENSAR ALREDEDOR DE PERFORMANCE}

En la producción artística y metalúrgica que se reconoce elaborada por pobladores del actual territorio colombiano, en fechas y estudios señalados entre el 300 y el 1520 de nuestra era Lleras (2000), se observa algunas figuras antropomorfas creadas e identificadas por la Ilamada cultura muisca en la Cordillera Oriental. Estas figuras, denominadas votivas o tunjos, presentan diferentes características en su representación. Uno de los criterios al identificarlas son los elementos que los acompañan o la postura de su cuerpo. Respecto a la posición corporal destaca la figura humana sentada y en varios casos sentada en un banco. Lleras (2000)

Esta representación se encuentra no solo en la zona arqueológica mencionada sino también en varias zonas arqueológicas de Colombia. Se observa entonces desde este escrito el estar sedente como acción, el silencio y el pensar como acción.

Es así como se retoma la idea del estar, del estar - pensándose desde la generación de preguntas, y dejar así la imagen que surge de los pensadores que al pensar están y al estar son materialidad. Al tiempo que el habla y la acción surgen como materialidad de ese pensar.

Como lo escribe Cornago en la introducción que realiza a Estética de lo performativo de Erika Fischer - Lichte (2011) "éste es el gesto - físico - con el que Nietzsche se pone en escena, se realiza como cuerpo que piensa, como intelectual o como artista, en definitiva, como persona que piensa y pensando hace, la teatralización del pensamiento" (Fischer-Lichte, 2011, p. 8). 
La figura de los pensadores, se observarán en la historia del arte retomando la imagen del Renacimiento con El Pensador de Miguel Ángel en su representación de Lorenzo de Médici, luego en el siglo XIX, Rodin mirando a Dante Aligieri como el poeta que piensa su obra y que da lugar al Pensador; el juez en la puerta del Infierno, y en el arte de la época precolombina, las imágenes de los pensadores en esculturas en pequeño formato correspondientes a las zonas arqueológicas o culturas Tumaco, Quimbaya y Muisca en Colombia, las cuales hacen alusión al Sabedor o al Gran Padre de sus clanes. Todos son ejemplos e imágenes a manera de ilustrar algunas reflexiones desde la estética de lo performativo. El actuar y el hablar que precedió, que estuvo latente y el que se llevó a "escena" antes, durante y después del pensar.

El "objeto" artístico alrededor del cual este artículo propone una reflexión estética bajo una mirada de acción performativa, es el mito del Hombre Sentado, estudiado por Urbina (1994) en algunas regiones del Amazonas colombiano.

Dewey (2004) propone revisar diferentes significados del pensamiento refiriendo que hay distintas maneras en que los seres humanos piensan realmente y la posibilidad de modificar la propia manera de pensar.

Al revisar diferentes maneras de pensar propone que los seres humanos tienen la capacidad de decidir la forma de pensar, sugiere a la vez que hay una manera de pensar que puede ser la mejor entre las que analiza.

Al respecto sostiene que el pensamiento reflexivo, que consiste en "darle vueltas a un tema en la cabeza y tomárselo en serio con todas sus consecuencias" (p. 21) es la mejor manera de pensar. Caparros (1998), en el prólogo que realiza a la edición española de Dewey, asemeja este pensamiento reflexivo al método científico, desde lo que este pensamiento es: "conjetura, selección de hipótesis, comprobación crítica, experimentación, búsqueda imaginativa de lo nuevo, curiosidad permanente" (Caparros, 1998, prólogo). Desde Dewey (2004) se concluye que el resultado de todo aprendizaje es el pensamiento reflexivo, pero aún más puntual la actividad reflexiva. Sostiene que la vida es ante todo acción, y para resolver y superar aspectos prácticos de la vida en todas sus dimensiones el ser humano se servirá del pensamiento como un instrumento.

En cuanto al pensamiento reflexivo Dewey sostiene que es una cadena, una sucesión de cosas acerca de las cuales se piensa, una secuencia de ideas en la que cada idea determina la siguiente como su resultado y a su vez cada resultado remite a las ideas que le precedieron. En el pensamiento reflexivo los fragmentos sucesivos surgen unos de otros y se apoyan mutuamente. Cada fase es un paso de algo hacia algo. Cada fragmento o cada "término" del pensamiento deja un residuo que es utilizado en el término siguiente. El flujo de ideas se convierte en una cadena. En todo pensamiento reflexivo hay unidades definidas ligadas entre sí, de manera que finaliza produciéndose un movimiento sostenido hacia un fin común.

Pero también habla Dewey respecto a las cosas que no se perciben directamente a través de los sentidos, que no se ven, ni se oyen, ni se tocan, ni se saborean, ni se huelen. Puede haber algo de invención, algo distinto del fiel registro de la observación. Sin embargo, se presentan sucesiones más o menos coherentes de episodios o incidentes imaginativos, que se unen sin rupturas de continuidad entre sí. Las narraciones imaginativas abarcan todos los grados de coherencia interna: algunas son caóticas; otras, articuladas. Cuando guardan conexión interna, tienen la apariencia del pensamiento reflexivo; en mentes de capacidad lógica. 
Relacionando el mito de El Hombre Sentado, Urbina (1994), con los anteriores razonamientos, el mito tiene un algo grado de narración imaginativa, con una coherencia en la sucesión de situaciones, articuladas a su manera, para llegar a un gran fin y objetivo, en medio de esta narración se podría pensar en imágenes caóticas que bien no podrían tener una lógica en nuestro pensamiento pero, desde el acercamiento al estudio del mito se empieza a evidenciar y se podría intuir que propone cierto grado de pensamiento reflexivo.

Generalmente las empresas imaginativas preceden al pensamiento homogéneo. "En este sentido, un pensamiento o idea es una imagen mental de algo que está presente en la realidad, y el hecho de pensar es la sucesión de tales imágenes". (Dewey, 2004 p. 23)

Si Taylor (2011) concluye que performance "implica simultáneamente un proceso, práctica, acto, episteme, evento, modo de transmisión, desempeño, realización y medio de intervención en el mundo" (p.28) en este escrito se enfoca el mito del hombre sentado desde dos conceptos que en cierto modo pueden resultar opuestos o contradictorios a la idea de performance: el pensar y la quietud.

La simultaneidad de fragmentos que implicaría entonces el performance, remite a las reflexiones de Dewey (2004) cuando sostiene que la vida es ante todo acción, y para resolver y superar aspectos prácticos de la vida, en este caso del performance, en todas sus dimensiones el ser humano se servirá del pensamiento como un instrumento.

"El Padre Creador, sentado en el aire, averiguaba muchas cosas. Se sentó y comenzó a crear todas las cosas. Cerró sus ojos y apareció una bolita negrita, apareció entre algo que era nada. Al cerrar los ojos veía una bolita negra. Abría los ojos y no veía nada.
Cerraba los ojos de nuevo y esa bolita se agrandaba. Esa bolita es la que tenemos en los ojos, se agranda y se achica. Luego de mucho sufrir esa bolita que él vio vendría a ser su asiento (...)"

Fragmento de El Hombre Sentado -"Mito de Origen narrado por el Abuelo Sabedor Noé Siake" (López \& Román citados en Urbina 1994 p. 92)

En este contexto surge la importancia de acercarse nuevamente al término performance. Taylor (2011), lleva a pensar en uno de los problemas al usar el término performance y que genera la pregunta común para muchos si todo es performance, a lo cual responde que no, pero que igualmente "todo se puede analizar como performance" (p.24). Dirige la mirada hacia lo que éste implica y propone como acertada la designación "esponja mutante" que el teórico mexicano Antonio Prieto Stambaugh tiene como explicación y resume el término en cuestión.

El escrito de Taylor (2011) invita a reflexionar sobre la idea que "hay temas que no se pueden trabajar ni pensar desde un solo lugar" (p. 12) presenta el ejemplo del cuerpo como elemento clave en el performance, como el "lugar" donde el artista y el público espectador se conectan y dan vida a esa re -presentación pensada o improvisada. Empiezan a surgir los conceptos que dan vida a este análisis y recorrerán el escrito: la re - presentación es pensada. En este caso se analiza e intuye lo que el mito también contiene, cada presentación y narración de éste conlleva a ser pensada nuevamente, se presenta de forma oral, de forma "actuada" y de forma pensada, en la mente de quien narra y de quien escucha. Pero también ese pensar que en el mismo mito es generador de acciones y de una creación final.

Otro elemento que está latente es el lugar, como el cuerpo, en El Hombre Sentado se hace evidente la importancia del cuerpo como lugar 
que desarrolla la acción de narrar, de pensar y de presentarse sentado con toda la simbología que trae, pero también donde el público y el espectador se conectan. En el mito, así como en el rito ese lugar también entra a cobrar valor físico y simbólico. El lugar como espacio físico corresponde al coqueadero, es donde se prepara y se consume ritualmente la coca, en este lugar, se ha realizado una pequeña cavidad en el piso, en esa cavidad es donde se queman las hojas secas de yarumo que se mezclarán con las hojas de coca en polvo (Pineda; Candre \& Echeverry; Urbina, 1986 y 1992 citados en Urbina 1994).

En el performance el artista y el espectador se conectan, el Maestro o Sabedor y el discípulo y participantes del rito escuchan y participan al volver "Obra, durante las labores diurnas", las "Palabras que el Sabedor ha extraído y pronunciado en la noche" (Urbina 1994, p. 96) En el coqueadero el Sabedor, se ubica cerca de la cavidad del piso para presidir el rito nocturno, la cavidad simboliza el útero de la Madre Primordial, simbólicamente el Abuelo Maestro o Sabedor extrae de allí las Palabras que se harán Obra durante las acciones en el día, "mediante el accionar de las gentes que las escuchan" (Urbina, 1994)

Ampliando la definición de performance, se remitirá a la que propone Schechner (2011), quien instala una consideración temporal que caracteriza al performance como un acto que nunca se da por primera vez, como una conducta que es de por sí comportamiento repetido. Sostiene que esta repetición es lo que le da al performance su fuerza simbólica y reflexiva.

Esta definición contribuye a dirigir la mirada al rito y con él al mito que se narra, que se transmite en el Hombre Sentado, desde la idea de la repetición y su fuerza simbólica al ser contado, con las variantes que éste tiene según la tradición del Sabedor que lo narre y según a quién lo narre $\mathrm{y}$, por otro lado la aseveración de Schechner (2011), respecto al performance como un acto que nunca se da por primera vez. Se anota que mito no tendría una génesis, no se puede establecer temporalmente cuándo se pronunció por primera vez. Sin embargo, el mito, la narración de El Hombre Sentado presenta la génesis, es un mito cosmogónico:

"El Padre sentado entre el Silencio, maduraba silencios. Aún no se inventaba ni el trueno, ni el murmullo del viento entre las hojas, ni el rugido del tigre, ni el grito de las águilas, ni la voz como espina del zancudo (...) Fue así como los hombres nos formamos. Por eso nos sentamos frente al padre y cuando en el ritual la voz eleva, repetimos sus últimas palabras"

Fragmento de texto transcrito por Urbina (1994), basado en las enseñanzas de su maestro Chuumu Güio, cacique de Guaimaraya.

Como conducta restaurada, la conducta que ha sido manipulada, modificada y preservada, se lleva a pensar esa conducta en relación con un pasado y dentro de una convención que se reactiva. Schechner (2011) también advierte el performance en tanto creación o invención, como una "oportunidad para volver a ser lo que uno fue" (p. 34)

Respecto al mito del Hombre Sentado para volver al origen, al momento de rememorar la acción creadora del todo, en cierto modo al narrar el mito se vivencia, se hace parte de él y el Maestro pasa a ser el gran Padre mientras narra el mito a su discípulo que escucha sentado frente a él, frente a "las gentes" que lo escuchan.

Es así como el objeto de estudio propuesto, se analiza desde posibilidades de ser asumido como acción performativa, teniendo en cuenta estudios y acercamientos ya realizados por 
autores que han mirado la opción del ritual y el mito como performance.

Se continúa pensando así entorno a la pregunta ¿El pensar y el estar sedente, se pueden presentar como actos performativos en el Hombre Sentado, mito del Amazonas colombiano?

\section{SEGUNDO MOMENTO}

\section{RITUAL Y MITO}

El objeto de estudio se dirige hacia una imagen de la iconografía de algunas culturas precolombinas en Colombia; el hombre sentado, especialmente figuras tridimensionales de pequeño formato que aparecen de manera recurrente en algunas de las zonas arqueológicas identificadas en el país, pero también en los pictogramas y petroglifos del arte rupestre.

La imagen de El Hombre Sentado, que se presenta repetitivamente, con variantes en diferentes regiones de la geografía colombiana, con un reducido conocimiento en torno a su simbología o su razón de ser, es el motivo que lleva a asumir el estudio de ésta desde lo performativo, del mito precolombino como "objeto" artístico válido de reflexión "estética".

Teniendo entonces definido el ritual y mito de El Hombre Sentado como objeto de estudio, se hace reconocimiento a las investigaciones que de éste ha realizado el profesor Fernando Urbina (1994) de manera sistemática y minuciosa en la descripción del ritual y el mito, desde su propia vivencia como discípulo de un Maestro o Abuelo Sabedor en la región de Araracuara en el curso medio del río Caquetá, investigaciones que permiten presentar este acercamiento de análisis reflexivo entorno a performance y ritual.

La palabra performance llevará a pensar inmediatamente en un desempeño, en una acción que desencadena otra acción y ésta en otras, la importancia del manejo de la palabra, en Fischer - Lichte (2011) se encuentra un referente clave, comentando a Austin, dirige la atención a los enunciados performativos, que no sólo dicen algo, la palabra lleva y genera la acción, lo que enuncia genera realidad, los enunciados performativos crean lo que expresan.

Desde el mito se asume la Palabra, si se remite a El Hombre Sentado, en el rito El Sabedor retrocede hacia el origen y busca allí las "Palabras-fuertes", las palabras que se vuelven Obra, crean lo que expresan en las acciones de las gentes que las han escuchado. Coincidiendo nuevamente con Schechner (2011) respecto a la conducta restaurada, en cuanto EI Sabedor, éste aparece como el recién engendrado y nacido, lleno del poder del origen que le permite a su vez engendrar y crear, repitiendo a escala cotidiana el paradigma del Padre y del Hijo primordiales, advirtiendo desde el performance, en tanto creación o invención, esa "oportunidad para volver a ser lo que uno fue" (Schechner, 2011 p. 34)

El performance ocurre como hecho artístico, se explica como un hecho vivido que lleva a que el espectador resulte inevitablemente involucrado.

La palabra, generando como acción lo que enuncia, generando realidad, crea lo que expresa, lo que conecta al mito ... la palabra como narración y acción reproduce el mito.

Desde esta idea, se logra un acercamiento a la obra El ritual de la serpiente de Aby Warburg (2004) como un encuentro con el estudio y la vivencia del ritual, que al leerlo se convierte en una forma de entender el acontecimiento y la vivencia de éste como espectador, pero también como espectador que enfrenta ese desajuste frente a las prácticas rituales que pretende analizar, y en las cuales también está inmerso.

En Warburg (2004) se vislumbran mitos y simbolismos que se perciben y se leen como 
acciones, donde el movimiento es protagonista desde la narración, desde la descripción y desde los elementos que intervienen en éste.

Warburg (2004), se muestra interesado en leer los simbolismos que encarnan tiempo y espacio, en los que el movimiento es inherente a ellos.

Una pintura de una línea en zigzag que representa una escalera simboliza la casauniverso con techo escalonado. Esta pintura, nos dice Warburg (2004), la observó en una parroquia de Laguna y la comparó con las que fabrican los indios Pueblo.

El simbolismo de esta escalera reside en el devenir, en los ascensos y descensos de la naturaleza, se presenta la escalera y el escalón como "símbolo de lucha entre lo alto y lo bajo en el espacio, de la misma forma que el círculo -la serpiente enrollada- simboliza el ritmo del tiempo"

"El ser humano, que ha dejado de caminar en cuatro patas para hacerlo en posición erecta, y que por lo tanto necesita de un instrumento para vencer la fuerza de gravedad cuando mira hacia arriba, ha inventado la escalera para ennoblecer sus deficiencias con respecto al animal. El hombre, que a la edad de dos años aprende a caminar, percibe la felicidad del escalón porque, como criatura que tiene que aprender a andar, recibe al mismo tiempo la gracia de poder elevar la cabeza. El movimiento ascendente es el acto humano por excelencia, que busca elevar al hombre de la tierra al cielo: es el verdadero acto simbólico que confiere al hombre que camina nobleza de mantener la cabeza levantada, mirando hacia lo alto" (Warburg, 2004 p. 26)

En esta narración, de los mitos en la cosmología de los indios Pueblo, el contemplar el cielo, es un hecho que contiene implícita la acción del movimiento de la cabeza, de los ojos. Ese movimiento lleva también intrínsecamente en el actuar un movimiento simbólico; el elevar al hombre de la tierra al cielo, el mirar hacia lo alto, hacia el cielo "la gracia y a la vez la maldición de la humanidad" (Warburg 2004 p.26)

Sin embargo, nos recuerda este autor que la representación de la casa-universo no es una cosmología apaciguada, está presentando el mundo aterrador que se encuentra al mirar o al estar abajo, el lugar donde el amo es la serpiente.

Ese movimiento ascendente como acto humano por excelencia que describe Warburg (2004) y que le confiere nobleza al hombre que camina, se puede encontrar en contraposición al análisis que empieza a generar interrogantes en Urbina (1994) al presentar al hombre sedente, y cuya quietud se analiza y considera en este escrito como una acción que implica movimiento en sí misma.

Urbina (1994) reflexiona en el hecho de estar de pie y con sus palabras afirma "quien se pone de pie asciende, persigue elevarse, estar por encima de..." el ser que está de pie, "se ubica así más cerca del poder que, supuestamente reside en lo alto" (...) "Se supera". "Lo superior se ubica arriba, es luminoso". (p.85)

Opuesto a ese mirar hacia lo alto que rescata Warburg (2004), también está el pensamiento y la concepción del inframundo, estudiado por Urbina (1994) en algunas comunidades indígenas del Caquetá.

"El mal reside abajo, en los inframundos, en lo inferior, en lo oscuro. Ha de ser tapado, aherrojado, lo superior ha de controlarlo sobreponiéndose sobre lo perverso que reclama la sombra" (Urbina, 1994 p.85) 
Para el presente objeto de estudio se reflexiona alrededor del hecho de estar sentado, "el hombre sentado resultará síntesis del arriba y del abajo; no reniega ni de lo uno ni de lo otro; los acoge: éxtasis que retrotrae el origen; madurez del pensar sereno" (Urbina 1994 p. 105)

Retomando el mito de El Hombre Sentado como ritual y posibilidad de análisis desde lo performativo, se dirige la atención a FischerLichte (2011), al referirse al performance Lips of Thomas por la artista yugoslava Marina Abramovic, haciendo notar particularidades que lo conectan con el ritual, así como con el espectáculo. Respecto a la condición de ritual resalta que aquel performance logró "una transformación de la artista y la de algunos espectadores", pero sin embargo no tuvo la consecuencia de "un cambio de estatus público o de identidad" (p. 32) característica que analiza como propia del ritual.

Fischer-Lichte (2011) mencionando a Austin, habla de enunciados performativos y cómo debe haber unas condiciones a cumplir para que éstos lo sean, concluyendo que deben ser ante todo unas condiciones institucionales y sociales, además de lingüísticas.

"La enunciación performativa se dirige siempre a una comunidad en una situación dada en la que alguno de sus miembros ha de estar presente representándola" (Austin citado por FischerLichte, 2011 p. 49)

Esa enunciación performativa puede entenderse en la pose que adopta el Sabedor en el coqueadero, lugar de la Palabra (Torres citado en Urbina 1994), al sentarse y ubicar sus brazos rodeando las rodillas a manera de representar un canasto, el cuerpo es metáfora de un receptáculo que contiene palabras, siendo éstas conocimiento. El Maestro o Abuelo Sabedor es así quien tiene la Palabra que otros van a escuchar de sus labios, entrega la Palabra a los hombres que lo rodean para que ellos vayan colmando su propio recipiente.

Urbina (1994) describe y narra los acercamientos a los grupos indígenas y el alto grado de aceptación que ha logrado, según nos hace saber en sus escritos. Así, trae una comprensión de los mitos e imágenes que acompañan a este acontecimiento ritual, $y$ tal vez performativo, que es hacia donde se trata de dilucidar la posibilidad de inscribirlo o examinarlo.

En este escrito, ritual se puede identificar con concepto, praxis, proceso, anhelo y experiencia, desde Schechner (2004), entendiendo que no son las únicas posibilidades de ampliación del término, las cuales pueden significar mucho o muy poco respecto a lo mucho o a lo poco que el ritual como acción performativa llegue a representar.

El ritual también se puede asumir aquí como "estructura con cualidades formales y relaciones definibles" (p.228).

"El ritual por lo general no lleva consigo el ser o contener ideas aceptadas, pero en muchos casos los sistemas dinámicos performativos generan nuevo material y recombinan acciones tradicionales en formas nuevas" (p.228)

Desde el mismo autor la idea de ritual se dirige al comportamiento del ser en su medio, el ritual entonces puede ser visto como el comportamiento ordinario que se restaura a través de la "exageración, la repetición y el ritmo en secuencias especializadas de comportamiento en servicio de funciones específicas como apareamiento, jerarquía o territorialidad". Tendría conexión con la conducta restaurada.

En el caso de El Hombre Sentado, la "función especifica" puede ir dirigida a varias opciones. Sería posible pensar la función de creación, desde el origen. Pero también pareciera que algunas de las funciones específicas que se 
mencionan anteriormente complementan o explican esa función general de creación.

Entonces este ritual podría ir encaminado a pensarse como jerarquía, desde la Palabra, a la que ya se ha estado haciendo referencia en este escrito, vemos que "La función del Abuelo Sabedor es estar armando y sosteniendo permanentemente el mundo humano, cosa que logra mediante las Palabras-primordiales, aquellas con las cuales los dioses no sólo forjaron la realidad primera, sino que se conformaron a sí mismos" (Urbina 1978, citado en Urbina 1994 p. 95)

"El Abuelo Sabedor mediante esas Palabras, se constituye en verdadero hombre (...) Y así, por realizar a cabalidad la esencia de lo humano, el Sabedor puede extenderla a quienes se acogen a su cuidado" (Urbina 1994 p. 95)

Como función de territorialidad, en el ritual de estudio, el Abuelo Sabedor es El-que-estásentado; al ser el Abuelo Sabedor quien conoce y maneja las palabras que ocultan los mitos -las Palabras-de-antigua- se constituye este Sabedor en "el poste central invisible de la maloca, la gran casa comunal, ámbito arquitectónico donde en antigua se acogía toda una gran familia extensa, el clan". (Urbina 1994 p. 94) Observando que este es todo un simbolismo que se repite y refleja al sentarse en el banco ritual, simbolismo que se repite en el mito narrado.

Como función de apareamiento, sería posible identificarla desde "El Sabedor que aparece como el recién engendrado y nacido, lleno del poder del origen que le permite a su vez engendrar y crear, repitiendo a escala cotidiana el paradigma del Padre y del Hijo primordiales" (Urbina 1994 p. 96)

Alrededor de la creación de estudios sobre los rituales que defiende Max Herrmann, en Fischer-Lichte (2011) aparece la jerarquía entre mito y ritual, nos ubica en la historia y aclara que mientras que en el siglo diecinueve se podía observar la primacía del mito sobre el ritual, a finales del siglo la relación entre ambos conceptos experimentó una inversión. Se asumirá entonces que el ritual pasó a tener preponderancia sobre el mito, sin embargo, analizando el Hombre Sentado esta propuesta asume ambos momentos balanceados en cuanto a la fuerza y la cualidad generadora de situaciones, el uno acontece debido al otro, cada uno tanto rito como mito crean una sucesión de acciones que se retroalimentan.

Se mencionó en párrafos anteriores la conducta restaurada, "la conducta en ejecución" (Schechner, 2011 p. 35) Desde la propuesta del autor y aludiendo a las ceremonias y rituales como performances culturales presenta esta particularidad sosteniendo que las conductas humanas son susceptibles a apartarse de su entorno de origen. Las analiza como secuencias de conducta que pueden reordenarse $\mathrm{o}$ reconstruirse.

La particularidad se presenta en cuanto al análisis del rito, surge así la pregunta si las conductas humanas, se apartan de su entorno físico de origen o más bien, transforman el entorno físico convirtiéndolo en un nuevo espacio en el cual la conducta, o las secuencias de conducta cobran esa vida propia que da origen una y otra vez a que el mito se comparta.

Se retoma la descripción de la situación en torno al lugar que Urbina (1994) describe para el ritual de El Hombre Sentado, el coqueadero, como el "lugar donde se prepara y consume ritualmente la coca" menciona que en el piso se puede encontrar una pequeña cavidad; "es allí donde se queman las hojas secas de yarumo, cuyas cenizas serán revueltas con el polvo de las hojas de coca que han sido previamente tostadas y apiladas" (p.96) Allí la conducta cotidiana empieza a girar, a reconstruirse en torno a lo simbólico del rito. Es precisamente cerca de dicha cavidad que se ubica el Abuelo 
quien preside el rito nocturno. "Esa oquedad simboliza el útero de la Madre Primordial. A él vuelve simbólicamente el Abuelo para extraer las Palabras que luego se harán Obra durante las labores diurnas, mediante el accionar de las gentes que las escuchan" (p. 96) Se puede ver el coqueadero como un lugar a manera de escenario que cobra o transforma su valor cuando el ritual le da un contenido, la última reflexión a partir de Alfred Klaar, mencionado por Fischer-Lichte (2011)

Teniendo en cuenta que la oralidad dentro del performance puede aparecer como un elemento más, también se puntualizará que cierto tipo de oralidad es asumida en sí misma como performance, ya que funciona en un presente, con cierta estructura predeterminada y a partir de la transmisión de la palabra. Los oradores, reelaboran las historias en la acción, no obstante, siguen ciertos comportamientos heredados y utilizan recursos retóricos para mantener viva la memoria y para ajustar nuevos elementos al discurso.

Para estudiar el mito de El Hombre sentado, el recurrir a la memoria semántica y a la memoria episódica, Fischer-Lichte (2011), resulta pertinente en cuanto a la recordación de palabras pronunciadas en el ritual y en la transmisión del mito, así como los pensamientos e interpretaciones que se generen en el discípulo $y$ aquellos otros individuos que en el momento del ritual también hacen presencia. Siendo muy posible entonces la amplificación de significados conceptuales que surgen de éste.

En concordancia con lo anterior, la experiencia humana, atravesada por dinámicas sociales cambiantes que forman "núcleos de sentido" en movimiento. De esta manera se pueden tener en cuenta las variaciones de significación, no solo del lenguaje, sino de otros núcleos que participan en el ritual, pensando en la metáfora del cuerpo que pasa a ser recipiente de la Palabra, en el banco ritual que tanto en éste como en el mito es el "basamento que posibilita desencadenar el proceso de ser generador del mundo" Urbina (1994). Se podría proponer que el banco es la metáfora del pensamiento.

Al dirigir la atención a El Hombre Sentado, ubicarse en el grupo de aquellos otros individuos que por dinámicas sociales tienen diferentes acercamientos tanto al ritual como al mito, es posible realizar aportes a su significación desde la forma en que puede ser posible una aproximación a éste -desde la lectura- el leer la descripción del ritual y la trascripción del mito, realizadas por un tercero, que tuvo el lugar de discípulo.

Sin embargo, desde las observaciones que realiza Urbina (1994) respecto a ese tercero que es discípulo se genera también la presencia de diferentes significaciones respecto a que el Maestro o Sabedor no comunica siempre igual el mito, primero teniendo en cuenta que existen varios Maestros y cada uno considera el mito desde una manera de visualizarlo, por otro lado, está un ingrediente clave, que es el acercamiento que pueda tener el discípulo que está recibiendo la transmisión de la sabiduría, ese discípulo como también lo dice Urbina (1994) puede ser el investigador que se acerca al Sabedor en busca de los conocimientos, en este contexto, dependiendo del grado de compromiso de éste hacia los saberes, el Maestro revelará más o menos cantidad de detalles, elegirá cuáles variaciones del mito comparte, teniendo presente, como las transcripciones de los mitos del Hombre Sentado nos dejan ver, que la acción, las acciones que se desenvuelven y los actores y elementos que en él intervienen también van variando a pesar que la esencia del mito sea la misma, en este caso la cosmogonía de la creación y del origen de todo.

"El Padre Creador sueña su obra; el papel del Hijo es hacer visible lo soñado, darle concreción. Pero si el curioso es consecuente con las obligaciones que impone una alianza y si 
persiste en las averiguaciones mostrando sumo interés, y demostrando asimilación del saber, y si se dan ciertas señales favorables, entonces será aceptado como discípulo y se sentará más asiduamente con el Sabedor para irse haciendo cargo de una tradición milenaria, pesada y exigente" (Urbina 1994)

Al ser quien adquiría formalmente el Poder, el Abuelo Sabedor, dirigía los ritos, hasta que llegaba el momento y el hecho de conferirle el Poder a su heredero, luego de haberle entregado aquellas tradiciones milenarias recibidas en su momento diligentemente, pero enriquecidas, a su vez, con su personal experiencia, según lo narra Urbina (1994). Puede decirse que estas secuencias de conducta tienen vida propia, pues la "verdad" original o la "fuente" de la conducta puede perderse, ignorarse o contradecirse (aun cuando aparentemente se le esté honrando y observando). El ritual de El Hombre Sentado, en un principio pareciera una secuencia dada por la formación y posterior ejecución y toma de posesión del Abuelo-Sabedor o Maestro, de su lugar en la ejecución de narración o transmisión de saberes como lo es este mito.

\section{TERCER MOMENTO}

\section{EL HOMBRE SENTADO}

Era la nada,

no había cosa alguna.

Allí el Padre palpaba lo imaginario,

\section{$(\ldots)$}

Ahora el Padre buscaba aquello que es nuestra vida,

el comienzo de nuestra historia,

pero sólo había un vacío.

\section{$(\ldots)$}

Tomó posesión de la nada, para luego sentarse en aquel plano,

que es nuestra tierra,

$$
\text { (..) }
$$

Luego se sentó en esta parte del universo,

que es nuestra tierra,

para crear el cielo:

tomó una parte de esa tierra

y con ella formó el cielo azul y las nubes blancas.

Transcripción de algunas partes de fragmento de mito cosmogónico del origen. (Urbina 1994, p. 88)

En Fischer-Lichte (2011) hay una disertación acerca del concepto "en vivo" de la acción performativa, se resalta, que esta distinción es producto de que existan los medios tecnológicos a través de los cuales las realizaciones escénicas quedan registradas. Puntualiza en que hoy por hoy, no hay ningún tipo de realización escénica que no sea retransmitido por los medios masivos de comunicación. Aclara la autora que, muchos artistas usan vídeos como parte del performance, otros lo desarrollan para la cámara, están las fotografías que será lo que ven los espectadores después o en muchos casos la única forma que el espectador acceda a estos eventos. Se pregunta la autora qué papel juega aquí el internet Se habla de un bucle de retroalimentación que sólo existe en la escena en vivo dentro de la co-presencia física del actor y el público, bucle que desaparece con el uso y aceptación de los medios como forma legítima.

El performance como registro o desde el registro, se ubica para el presente estudio de El Hombre Sentado, como registro escrito, es posible conocerlo y acercarse, en cierto modo vivirlo sin que exista la co-presencia física del Sabedor y el discípulo y grupo de individuos que en el "ritual en vivo" co - participan. A pesar de 
ser la lectura una acción de bastante quietud no deja de tener importancia el movimiento, pero más que éste se percibe que la co - presencia gira en torno a lo simbólico. Leer en un libro en físico o en digital, el mito y la descripción del ritual o su relato generará el nuevo "bucle" en la acción individual de ser lector y conectarse con una lectura, será la participación en el evento de conocer y leer lo que un tercero escribió (en este caso el profesor Urbina), a partir de su participación "en vivo" de la escena o del relato. Entonces no sólo el registro digital en cuanto vídeo o fotografía, es actualmente inevitable, sino que es posible considerar una forma válida el registro escrito para acceder a la realización escénica. Alguien que observó o vivió el ritual o el acto performativo lo registra desde la escritura y logra llevar a imagen las secuencias de acciones que se leen y al leerlas se hace partícipe de éste, permitiéndose al mismo tiempo la opción una vez más de repetición del ritual desde el acceso al registro.

Desde el campo teatral, para Schechner (2011) el performance permite atender al comportamiento corporal y así desplazar al texto escrito de su lugar central en la producción teatral. En el caso del ritual y narración del mito de El Hombre Sentado, el comportamiento corporal y el texto narrado cobrarían la misma importancia, ninguno desplaza al otro de su lugar.

En el mito del Hombre sentado se plantea la figura del "actor" en posición sedente, sentado en un pequeño banco y cómo su pensamiento va generando acciones que desencadenan imágenes vistas como situaciones

(Urbina, 1994) Dentro de una interpretación opuesta a aquella que ubica naturalmente lo superior arriba, se plantea que el poder viene de abajo; es el fundamento, es lo primero; sin ello nada puede aparecer. El hombre sentado está más cerca de la tierra, se planta, sin que por ello pierda la capacidad de mirar hacia lo lejano, mirar con atención para descubrir.
El autor hace referencia a la relación del Abuelo o Maestro Sabedor y el hombre sentado; relata que, en América india, el Sabedor se sienta en bancos sumamente bajos y durante las largas sesiones en el lugar de la Palabra, el coqueadero, el lugar más sagrado de la maloca, se desliza del banco de manera imperceptible a la pose en curruca. La simbología de esta acción y gestualidad está asociada "con la posición fetal, el Abuelo debe retraerse al origen para sacar de allí las Palabras-fuertes" (Urbina, 1994 p. 96)

"El accionar del Abuelo Sabedor tiene que ver con viajes. Desde su banco ritual se hunde en el inframundo, en la fábrica de los mundos, para ascender luego y dominar el conjunto" (Urbina, 1994 p. 105)

Urbina (1994) nos dice que, en el acto de aprendizaje ritual, el discípulo se sienta frente a su Maestro y suele acompañar el discurso del preceptor repitiendo las últimas palabras de la frase. El discípulo se torna su eco.

El Padre sentado entre el Silencio,

Maduraba silencios.

Aún no se inventaba ni el trueno,

$\mathrm{Ni}$ el murmullo del viento entre las hojas,

$(\ldots)$

¿Con quién puede hablar el dios?

Entonces vio su sombra.

Estaba allí, sentada.

Se inventó la palabra y el eco respondió

(el eco que es la sombra del sonido).

Fue así como los hombres nos formamos. 
Fragmento del mito de El Hombre Sentado transcrito por Urbina (1994) con base en las enseñanzas de su maestro Chuumu Güio, cacique de Guaimaraya p.106)

Sentarse, quietud, actitud sedente, conlleva en sí la acción en potencia, no sólo la acción de movimiento físico, sino la de pensar y crear.

El habla como palabra, acción del pensar. El pensar y la Palabra como conocimiento.

En este artículo confluyen temas de lo precolombino analizando el mito y la imagen desde la estética y desde el arte y como apoyo al proyecto Arte y creación en la formación docente en educación preescolar: el caso de regularidades y patrones. Grupo BIOMA².

Agradecimiento a la Universidad Colegio Mayor de Cundinamarca, por su patrocinio en la publicación.

\section{REFERENCIAS BIBLIOGRÁFICAS}

Dewey, J. (1989). Cómo pensamos. Nueva exposición de la relación entre pensamiento reflexivo y proceso educativo. España: Paidós. ISBN 84-7509-514-3

Fisher-Lichte, E. (2011). Estética de lo performativo. Madrid: Abada editores

Lleras, R. (2000). La geografía del género en las figuras votivas de la Cordillera Oriental. Boletín Museo del Oro, No 47 pp.1 - 21, Banco de la República, Bogotá. Recuperado el 1 de septiembre de 2020 de http://www.banrep.gov. $\mathrm{co} / \mathrm{museo} / \mathrm{boletin}$

Schechner, R. (2011). Restauración de la conducta en: Estudios avanzados de performance. México: Fondo de Cultura Económico. pp. $33-48$

2 Agradecimiento a la Universidad Colegio Mayor de Cundinamarca, por su patrocinio en la publicación.
--- . (2004). The future of ritual. Writings on culture and performance. Routledge. Taylor \& Francis e-Library

Taylor, D. (2011). Estudios avanzados de performance. Performance, teoría y práctica. México: Fondo de Cultura Económico pp. 7-28

Urbina, F. (1994). El hombre sentado: mitos, ritos y petroglifos en el río Caquetá. Banco de la República. Museo del Oro, Boletín No 36, Bogotá, Colombia, pp. 67-106.

Warburg, A. (2004). El ritual de la serpiente. México: Editorial sextopiso. 